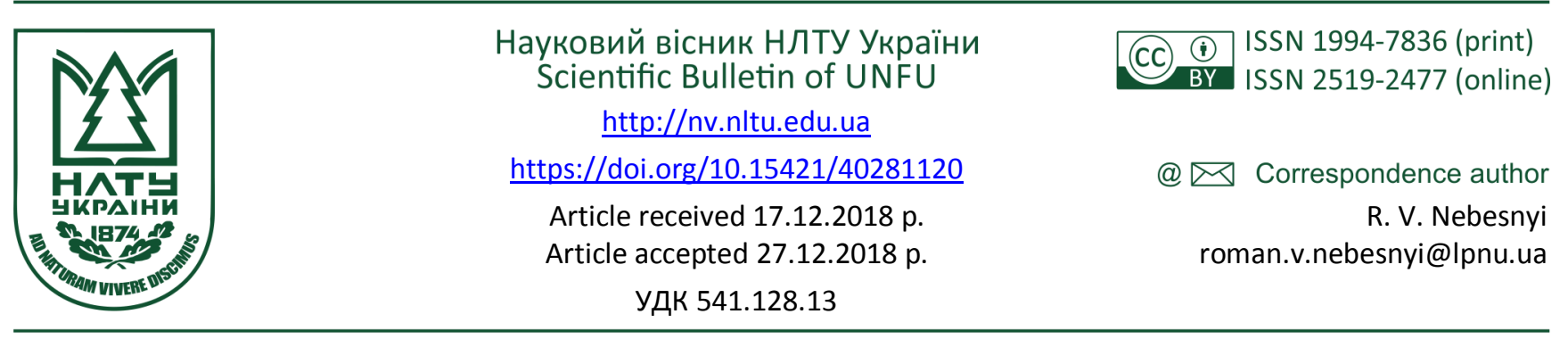

Р. В. Небесний

Національний університет "Львівська політехніка", м. Львів, Україна

\title{
ВИРОБНИЦТВО АКРИЛОВОЇ КИСЛОТИ: ПОРІВНЯННЯ ПРОМИСЛОВОГО ТА НОВИХ ПЕРСПЕКТИВНИХ МЕТОДІВ ЇЇ ОДЕРЖАННЯ
}

\begin{abstract}
Виконано порівняльний огляд основних перспективних методів одержання акрилової кислоти. Показано, що значного розвитку з огляду на доступність сировинної бази набув метод одержання акрилової кислоти з гліцерину (побічного продукту виробництва біодизелю), а також способом ферментації біомаси. Окрім цього, показано, що вдосконалення каталізаторів альдольної конденсації оцтової кислоти з формальдегідом в акрилову кислоту робить цей метод ії синтезу одним із найбільш конкурентних. Встановлено, що модифікація поруватої структури $\mathrm{B}-\mathrm{P}-\mathrm{W}-\mathrm{V}-\mathrm{O}_{\mathrm{x}} / \mathrm{SiO}_{2}$ каталізаторів процесу альдольної конденсації $є$ дієвим способом впливу на їхні каталітичні властивості. Оптимальним розміром пор B-P-W-V$\mathrm{O}_{\mathrm{x}} / \mathrm{SiO}_{2}$ каталізаторів $є 11-16$ нм. В оптимальних умовах (температура $380{ }^{\circ} \mathrm{C}$, час контакту 8 с) вихід акрилової кислоти в процесі альдольної конденсації оцтової кислоти з формальдегідом становить 68 \% за селективності ії утворення 91 \%. Розроблений каталізатор також $є$ ефективним у процесі окиснювальної конденсації метанолу з оцтовою кислотою. Особливістю цього методу $є$ те, що в процесі утворюються одночасно два цінні продукти - акрилова кислота та метилакрилат. Сумарний вихід акрилатів становить $54,7 \%$ за селективності їх утворення $80,1 \%$ (температура $400{ }^{\circ} \mathrm{C}$, час контакту 8 с). Розглянуто перспективи використання новітніх Se-вмісних каталітичних систем на мікрогелевій основі для низькотемпературного синтезу акрилової кислоти та метилакрилату з акролеїну.
\end{abstract}

Ключові слова: акрилатні мономери; альдольна конденсація; акролеїн; окиснення; гетерогенні каталізатори.

Вступ. Акрилова кислота (АК) - це цінний мономер, виробництво якого у світі становить близько 5,5 млн тонн щорічно. АК використовують для виробництва суперабсорбентів, фарб, диспергаторів, текстилю, допоміжних речовин тощо (Nafe, López-Martınez \& Dyballa, 2015; Peterson, Chapman \& Gallacher, 2014; Zhang et al., 2016; Peterson \& Chapman, 2013; Chu et al., 2015). Протягом останнього десятиліття продуктивність виробництва полімерних матеріалів на основі АК швидко зростає (Chu et al., 2015). Це зумовлює зростання ринку АК на 3-6 \% щорічно, яке буде продовжуватись у тривалій перспективі.

Найпоширенішим способом виробництва АК є двостадійне окиснення пропілену через проміжну стадію утворення акролеїну (Tanimoto, Nakamura \& Kawajiri, 2003). Цей метод характеризується хорошою економічною ефективністю та простотою технологічного оформлення, проте базується на нафтовій сировині, тому значно залежить від нестійкого ринку нафти. Протягом 2005-2014 pр. ціни на нафту були достатньо високими та спричинили проблему диверсифікації сировинної бази АК та високу актуальність розвитку нових методів виробництва АК. Отож, розроблення методів синтезу АК з відновлюваної сировини стала новою тенденцією. Тому найбільш перспективними методами є синтез АК на основі гліцерину та біомаси. Іншим методом, який також можна розглядати як метод синтезу АК з віднов- люваної сировини, є альдольна конденсація оцтової кислоти 3 формальдегідом (за схемою: біомаса - синтез-газ - метанол - оцтова кислота та формальдегід акрилова кислота).

Мета роботи - порівняти найбільш перспективні методи виробництва АК із традиційним - метод окиснення пропілену (на основі нафтопродуктів).

Матеріали та методи дослідження. У роботі виконано експериментальні дослідження щодо визначення впливу модифікації поруватої структури $\mathrm{B}-\mathrm{P}-\mathrm{W}-\mathrm{V}-$ $\mathrm{O}_{\mathrm{x}} / \mathrm{SiO}_{2}$ каталізаторів на їхню каталітичну активність у процесі альдольної конденсації ОК з ФА. Каталізатори готували методом просочення носія насиченим розчином компонентів активної фази. Атомне співвідношення компонентів у каталізаторі B:P:V:W становить 3:1:0,18:0,12. Реакції альдольної конденсації ОК з ФА здійснювали в температурному діапазоні від 573 до 673 К за часу контакту 8 с та еквімолярному співвідношенні вихідних реагентів.

Як джерело ФА для дослідження процесу альдольної конденсації використовували формалін, який одержували 3 параформу безпосередньо перед здійсненням реакції. Дослідження проводили в реакторі проточного типу з імпульсною подачею реагентів і стаціонарним шаром каталізатора. Продукти реакцій аналізували хроматографічним методом.

Інформація про авторів:

Небесний Роман Володимирович, канд. техн. наук, пров. наук. співробітник, кафедра технології органічних продуктів.

Email: roman.v.nebesnyi@lpnu.ua

Цитування за Дсту: Небесний Р. В. Виробництво акрилової кислоти: порівняння промислового та нових перспективних методів її одержання. Науковий вісник НЛТУ України. 2018, т. 28, № 11. С. 108-111.

Citation APA: Nebesnyi, R. V. (2018). Acrylic acid production: comparison of industrial and new promising methods of its synthesis. Scientific Bulletin of UNFU, 28(11), 108-111. https://doi.org/10.15421/40281120 


\section{Результати дослідження та їх обговорення}

1. Синтез акрилової кислоти з гліцерину. Інтерес до цього методу збільшився внаслідок біодизельного буму. Причиною цьому був побічний продукт виробництва біодизелю - гліцерин, який став широкодоступною та порівняно недорогою сировиною. С численні публікації, що стосуються окиснення гліцерину в акролеїн та акрилову кислоту. Каталізатори складу $\mathrm{W}-\mathrm{V}-\mathrm{Nb}-\mathrm{O} \epsilon$ одними 3 найбільш ефективних (Chieregato, Basile \& Concepción, 2012). Також трапляються дані про окиснення гліцерину до акрилової кислоти на багатофункціональних каталізаторах (Chieregato, Soriano, Basile, 2014). Проте максимальний вихід АК не перевищує 50,5\%, що є недостатнім для промислового використання.

2. Синтез акрилової кислоти з біомаси. Виробництво АК з відновлюваної сировини здійснюють способом бродіння біомаси до молочної кислоти з подальшою її дегідратацією до АК. У науковій літературі є дані, що ефективними каталізаторами для дегідратації молочної кислоти до АК є сульфати $\mathrm{Ca}-\mathrm{Cu}-\mathrm{Na}-\mathrm{K}$ (Zhang, Lin \& Cen, 2008). Виділення та очищення молочної кислоти 3 ферментативного середовища є складним процесом через необмежену розчинність молочної кислоти у воді. Альтернативний метод полягає в синтезі спочатку метиллактату, а потім його очищення способом дистиляції з подальшим гідролізом метиллактату до молочної кислоти. Встановлено, що метиллактат можна використати як сировину для виробництва інших хімічних речовин, таких як акрилова кислота за порівняно менших енергетичних затратах (Zhang et al., 2008). Вихід АК або загальний вихід АК та метилакрилату становить близько $63 \%$. Основним недоліком цього підходу (АК на основі біомаси) є значна тривалість процесу (Gao, Мa \& Xu, 2011) i, як наслідок, низька продуктивність реакційного обладнання.

3. Синтез акрилової кислоти за реакціями конденсаціï. Реакції альдольної конденсації карбонільних сполук $є$ одними 3 найбільш перспективних методів виробництва акрилатних мономерів. Синтез АК за схемою: біомаса - синтез-газ - метанол - оцтова кислота та формальдегід - акрилова кислота, можна вважати відновлюваним методом синтезу акрилової кислоти. Всі стадії зазначеного методу, окрім останньої, реалізовано в промисловості. Проте альдольна конденсація оцтової кислоти (ОК) з формальдегідом (ФА) до АК не має промислової реалізації через недостатню продуктивність відомих на сьогодні каталізаторів. Проте кількість досліджень, які стосуються цього процесу, останнім часом зросла. Було використано різні підходи для розроблення ефективних каталізаторів: розроблення каталізаторів кислотного типу (Yang et al., 2016), каталізатори основного типу (Guo et al., 2017), а також каталізатори біфункціонального типу (Yang et al., 2015). Для розроблення каталізаторів використовували різні носії: $\mathrm{SiO}_{2}, \mathrm{TiO}_{2}$, $\mathrm{ZrO}_{2}, \mathrm{Nb}_{2} \mathrm{O}_{5}, \mathrm{Sb}_{2} \mathrm{O}_{3}, \mathrm{Al}_{2} \mathrm{O}_{3}$, а також було встановлено вплив взаємодії оксид-носій на ефективність каталізатора в процесах альдольної конденсації (Zhao et al., 2016). Отож, якісний та кількісний склад каталізатора, кислотно-основні характеристики поверхні каталізаторів та взаємодію оксиду-носія було визначено як чинники, що впливають на каталітичні властивості в реакціях альдольної конденсації карбонільних сполук.

В останніх дослідженнях було встановлено, що використання носія SBA-15 для каталізатора V-P-O може бути ефективним у синтезі АК та метилакрилату (Hu et al., 2016). Ефективність цього каталізатора було пов'язано $з$ його кислотно-основними властивостями, що зумовлено типом носія та атомним співвідношенням P/V.

У наших попередніх дослідженнях було встановлено, що каталізатори складу $\mathrm{B}-\mathrm{P}-\mathrm{W}-\mathrm{V}-\mathrm{O}_{\mathrm{x}} / \mathrm{SiO}_{2} \epsilon$ досить ефективні в процесі альдольної конденсації ОК з ФА до АК у газовій фазі (Nebesnyi, 2015). Встановлено оптимальне атомне співвідношення компонентів каталізатоpa - B:P:V:W = 3:1:0,18:0,12. Застосування цього каталізатора дає змогу досягти виходу АК за один прохід 57 \%.

Відомо, що ефективність твердих каталізаторів залежить від їх фізико-хімічних властивостей, зокрема: питомої поверхні, параметрів поруватої структури тощо. Зазначені вище характеристики можна змінювати у широкому діапазоні за допомогою гідротермальної обробки каталізатора (ГТО). Тому було важливо встановити вплив гідротермальної обробки силікагелевого носія В$\mathrm{P}-\mathrm{W}-\mathrm{V}-\mathrm{O}_{\mathrm{x}} / \mathrm{SiO}_{2}$ каталізатора на його властивості в реакціях конденсації. Отже, для регулювання поруватої структури носія останній піддавали ГТО в інтервалі температур 100-250 ${ }^{\circ} \mathrm{C}$ протягом 3 год.

Як видно з рис. 1, максимум на кривих розподілу пор за розміром (PSD) зміщується у напрямку до більш високих значень діаметра пор під час підвищення температури ГТО. Каталізатор, нанесений на силікагель, що підданий ГТО за температури $150{ }^{\circ} \mathrm{C}$, характеризується найвищою каталітичною ефективністю. Збільшення ефективності каталізаторів можна пов'язати здебільшого зі зміною розподілу розмірів пор поверхні каталізаторів. Окрім підвищення механічної міцності гранул силікагелю, які піддають гідротермальній обробці, відбувається сповільнення процесів коксоутворення та, як наслідок, збілышення терміну роботи каталізаторів.

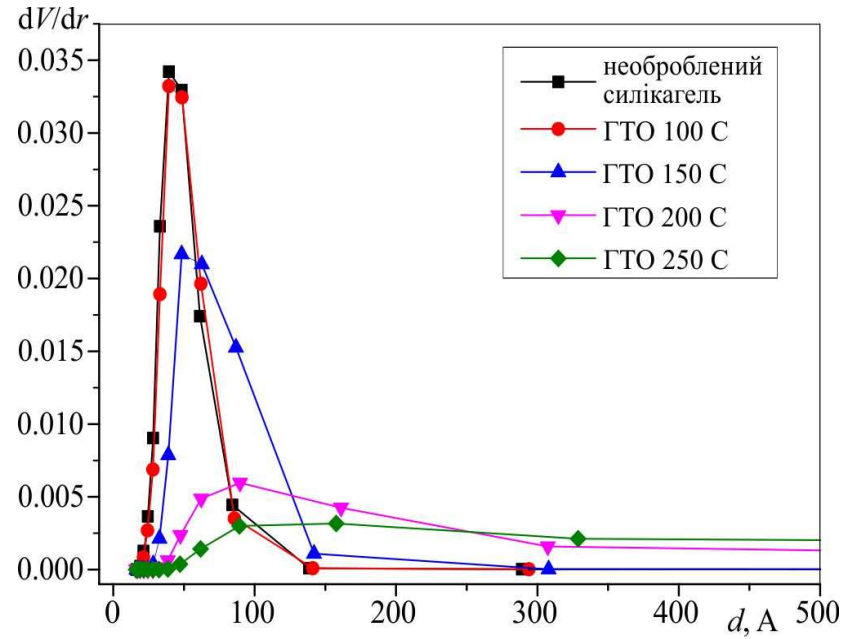

Рис. 1. Криві PSD для B-P-W-V-O кагелі, обробленому за різних температур

Як видно з рис. 2, залежність виходу акрилової кислоти від розміру пор каталізатора має максимум за діаметра пор 12,6 нм. Вихід АК за один прохід при цьому становить $67,6 \%$.

Каталізатори B-P-W-V-O $\mathrm{O}_{\mathrm{x}} / \mathrm{SiO}_{2}$ також ефективні в процесі окиснювальної конденсації (окислювальна конденсація метанолу з оцтовою кислотою до акрилової кислоти та метил акрилату) (табл. 1). Особливістю цього процесу $є$ одночасне отримання двох цінних мономерів - АК та метилакрилату. 


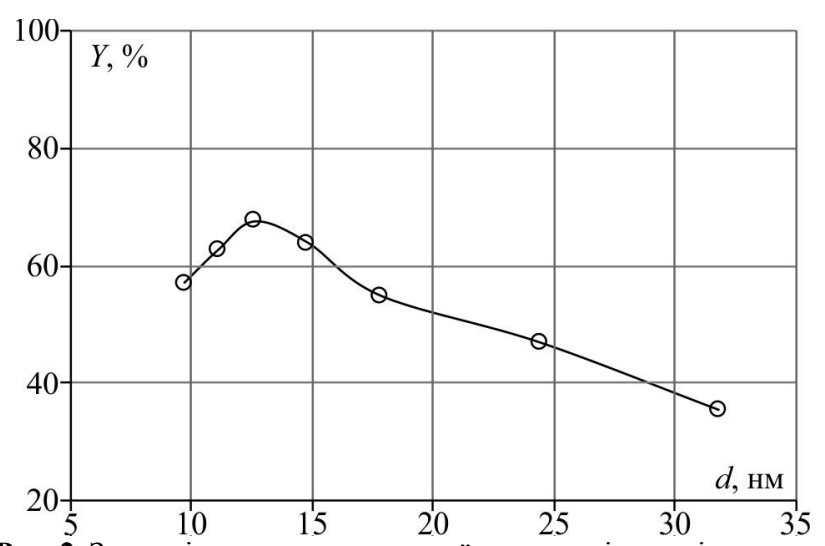

Рис. 2. Залежність виходу акрилової кислоти від розміру пор каталізатора. Температура ГТО $150^{\circ} \mathrm{C}$, а реакції $375^{\circ} \mathrm{C}$

Табл. 1. Ефективність каталізаторів B-P-W-V-O $/ \mathrm{SiO}_{2}$ у процесі альдольної конденсації та окиснювальної конденсації (за оптимальних умов)

\begin{tabular}{|c|c|c|c|c|}
\hline \multirow{3}{*}{ Параметр Процес } & \multicolumn{2}{|c|}{$\begin{array}{c}\text { Альдольна } \\
\text { конденсація }\end{array}$} & \multicolumn{2}{|c|}{$\begin{array}{c}\text { Окислювальна } \\
\text { конденсація }\end{array}$} \\
\hline & \multicolumn{2}{|c|}{ каталізатор } & \multicolumn{2}{|c|}{ каталізатор } \\
\hline & $\begin{array}{c}\text { необроб- } \\
\text { лений }\end{array}$ & $\begin{array}{c}\text { обробле- } \\
\text { ний }\end{array}$ & $\begin{array}{c}\text { необроб- } \\
\text { лений }\end{array}$ & $\begin{array}{c}\text { обробле- } \\
\text { ний }\end{array}$ \\
\hline Конверсія, \% & 64 & 75 & 38 & 57 \\
\hline $\begin{array}{c}\text { Селектив- } \\
\text { ність, \% }\end{array}$ & 89 & 91 & 93 & 93 \\
\hline $\begin{array}{c}\text { Вихід за один } \\
\text { прохід, \% }\end{array}$ & 57 & 68 & $32 *$ & $50 *$ \\
\hline
\end{tabular}

Примітка: * Сумарний вихід акрилової кислоти та метилакрилату.

\section{4. Синтез акрилової кислоти окисненням пропіле-} ну (з нафтової сировини). Спосіб виробництва АК 3 пропілену через проміжну стадію утворення акролеїну набув популярності у 80-х роках ХХ ст. Вихід АК на основі пропілену становить близько 81 \% (Dubois et al., 2008). Обидві стадії проводять у реакторах проточного типу зі стаціонарним шаром каталізатора. Типово температура окиснення пропілену становить $350{ }^{\circ} \mathrm{C}$, а температура процесу окиснення акрелеїну $320^{\circ} \mathrm{C}$. Реакційний потік надходить на другу стадію без розділення.

Відносна стабілізація ринку нафти після 2014 р. сприяла тому, що цей метод виробництва АК залишається прийнятним щодо економічної ефективності. Водночас активно ведуть дослідження стосовно прямого окиснення пропану до АК (Klanner, Dieterle \& Schindler, 2008). Перевагою цього методу одержання АК $є$ низька вартість пропану, проте через низьку селективність утворення АК цей спосіб все ще знаходиться на стадії розроблення.

Враховуючи той факт, що акролеїн є проміжним продуктом багатотонажного виробництва АК (за діючим методом синтезу АК з пропілену), а також проміжним продуктом одного 3 найбільш перспективних альтернативних (зелених) методів виробництва АК (на основі гліцерину), підвищення ефективності каталізаторів окиснення акролеїну викликає значне зацікавлення.

Одним із найбільш перспективних методів синтезу АК окисненням акролеїну є високоселективне окиснення ненасичених альдегідів пероксидом водню у присутності неорганічних Se-вмісних каталізаторів (Pikh et al., 2016). Проте використання водорозчинних каталізаторів зумовлює проблему розділення реагентів, відділення та повторного використання каталізаторів. Для вирішення цієї проблеми ми розробили новий тип каталізаторів окиснення акролеїну - Se-вмісні мікрогелеві коло- їдні органічні каталізатори. Використання розроблених каталізаторів дає змогу конвертувати акролеїн в АК або метилакрилат (у середовищі метанолу) з високим виходом та селективністю (до $97 \%$ ). Іншою великою перевагою цих каталізаторів $\epsilon$ їхня простота відділення та повторного використання. Окрім цього, процес відбувається за м'яких умов (50 ${ }^{\circ} \mathrm{C}$ за атмосферного тиску) (табл. 2).

Табл. 2. Порівняння методів синтезу акрилової кислоти та метилакрилату

\begin{tabular}{|c|c|c|c|c|c|}
\hline \multirow[b]{2}{*}{$\begin{array}{l}\text { Метод виробництва } \\
\text { акрилової кислоти }\end{array}$} & \multirow{2}{*}{ 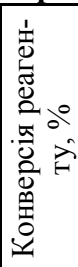 } & \multicolumn{2}{|c|}{$\begin{array}{c}\text { Селек- } \\
\text { тивність }\end{array}$} & \multirow{2}{*}{ 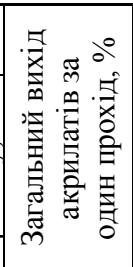 } & \multirow[b]{2}{*}{$\begin{array}{l}0 \\
0 \\
ن\end{array}$} \\
\hline & & 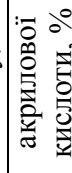 & 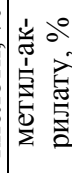 & & \\
\hline $\begin{array}{l}\text { Окиснення акролеїну } \\
(\text { промисловий процес) }\end{array}$ & 94 & 89 & 0 & 84 & 320 \\
\hline $\begin{array}{l}\text { Окиснювальне дегідрування } \\
\text { гліцерину }\end{array}$ & 100 & 50.5 & 0 & 50.5 & 265 \\
\hline $\begin{array}{l}\text { Конверсія біомаси через мо- } \\
\text { лочну кислоту }\end{array}$ & - & - & - & 63.7 & 330 \\
\hline $\begin{array}{l}\text { Конверсія біомаси через ме- } \\
\text { тиллактат }\end{array}$ & 76 & 54.3 & 26.4 & 61.3 & 400 \\
\hline $\begin{array}{l}\text { Альдольна конденсація оцто- } \\
\text { вої кислоти та формальдегіду }\end{array}$ & 75 & 91 & 0 & 68 & 380 \\
\hline $\begin{array}{l}\text { Окиснювальна конденсація } \\
\text { метанолу та оцтової кислоти }\end{array}$ & 57 & 89 & 4 & 50 & 400 \\
\hline $\begin{array}{l}\text { Окиснювальна естерифікація } \\
\text { акролеїну з метанолом, вико- } \\
\text { ристовуючи Sе-вмісний мік- } \\
\text { рогелевий каталізатор }\end{array}$ & 90 & 7 & 92 & 89 & 50 \\
\hline
\end{tabular}

Висновки. Враховуючи підсумкові результати (табл. 2), методи синтезу акрилової кислоти та метилакрилату альдольною конденсацією оцтової кислоти 3 формальдегідом, ферментацією біомаси та окисненням гліцерину є висококонкурентними. Перевага кожного 3 цих методів має значну чутливість до кон'юнктури відповідних сировинних ринків. Водночас промислова реалізація розглянутих методів синтезу акрилової кислоти сприятиме розширенню сировинної бази виробництва акрилової кислоти, а також зниженню її вартості.

\section{Перелік використаних джерел}

Chieregato, A., Basile, F., \& Concepción, P. (2012). Glycerol oxidehydration into acrolein and acrylic acid over $\mathrm{W}-\mathrm{V}-\mathrm{Nb}-\mathrm{O}$ bronzes with hexagonal structure. Catal. Today J., 197, 58-65. https://doi.org/10.1016/j.cattod.2012.06.024

Chieregato, A., Soriano, M. D., \& Basile, F. (2014). Study of the gasphase glycerol oxidehydration on systems based on transition metals $(\mathrm{Co}, \mathrm{Fe}, \mathrm{V})$ and aluminium phosphate. J. Applied Catal. B: Environmental, 150-151, 37-46. https://doi.org/10.1016/j.mcat.2018.05.020

Chu, H. S., Ahn, J. H., Yun, J., Choi, I. S., Nam, T. W., Cho, K. M. (2015). Direct fermentation route for the production of acrylic acid. Metab. Eng., 32, 23-29. https://doi.org/10.1016/i.ymben.2015.08.005

Dubois, J.-I., Desdevises, F., Desdevises, F., \& Serreau, S. (2008). US Pat., 734519, 18 Mar 2008.

Gao, C., Ma, C., \& Xu, P. (2011). Biotechnological routes based on lactic acid production from biomass. J. Biotechnology Advances, 29, 930-939. https://doi.org/10.1016/j.biotechadv.2011.07.022

Guo, X., Yang, D., Zuo, C., Peng, Z., Li, C., \& Zhang, S. (2017). Catalysts, Process Optimization, and Kinetics for the Production of Methyl Acrylate over Vanadium Phosphorus Oxide Catalysts. Ind. Eng. Chem. Res., 56, 5860-5871. https://doi.org/10.1021/acs.iecr.7b01212 
Hu, J., Lu, Z., Yin, H., Xue, W., Wang, A., Shen, L., \& Liu, S. (2016). Aldol condensation of acetic acid with formaldehyde to acrylic acid over $\mathrm{SiO}_{2}$, SBA-15-, and HZSM-5-supported V-P-O catalysts. $J$. of Ind. and Eng. Chem., 40, 145-151. https://doi.org/10.1016/j.jiec.2016.06.018

Klanner, C., Dieterle, M., \& Schindler, G.-P. (2008). US Pat 7388106, 17 June 2008.

Nafe, G., López-Martınez, M., \& Dyballa, M. (2015). Vapor-phase catalytic dehydration of lactic acid to acrylic acid over nano-crystalline cerium phosphate catalysts. J. Catal, 329, 413-424. https://doi.org/10.1007/s13203-016-0150-5

Nebesnyi, R. (2015). Study into conditions for the interaction between different types of transport at intermodal terminals. Eastern-European Journal of Enterprise Technologies, 6(73), 13-16. https://doi.org/10.15587/1729-4061.2018.151929

Peterson, C., \& Chapman, J. (2013). US Pat., 20130085303 A1, 4 Apr 2013.

Peterson, C., Chapman, J., \& Gallacher, J. (2014). US Pat., 8864950 B2, 21 Oct 2014.

Pikh, Z., Nebesnyi, R., Ivasiv, V., Pich, A., \& Vynnytska, S. (2016). Oxidation of Unsaturated Aldehydes by Organic Peracids. Chemistry \& Chemical Technology, 10(4), 401-411. Retrieved from: http://lp.edu.ua/news/2017/naukovyy-zhurnal-journal-chemistrychemical-technology-volume-10-number-4-2016
Tanimoto, M., Nakamura, D., \& Kawajiri, T. (2003). US Pat., 6545178, 08 Apr 2003.

Yang, D., Li, D., Yao, H., \& Zhang, G. (2015). OpenFOAM Computational Fluid Dynamic Simulations of Two-Phase Flow and Mass Transfer in an Advanced-Flow Reactor. Ind. Eng. Chem. Res.,54, 6865-6873.

Yang, D., Sararuk, C., Suzuki, K., Li, Z., \& Li, C. (2016). Effect of pore size distribution and particle size of porous metal oxides on phosphate adsorption capacity and kinetics. Chem. Eng. J., 300, 160-168. https://doi.org/10.1016/j.cej.2018.09.202

Zhang, J., Lin, J., \& Cen, P. (2008). Catalytic dehydration of lactic acid to acrylic acid over sulfate catalysts. Canadian $J$. of Chem. Eng., 86, 1047-1053. https://doi.org/10.1002/cjce.20115

Zhang, J., Lin, J., Xu, X., \& Cen, P. (2008). Evaluation of Catalysts and Optimization of Reaction Conditions for the Dehydration of Methyl Lactate to Acrylates. Chinese J. of Chem. Eng., 16(2), 263264. https://doi.org/10.1016/S1004-9541(08)60073-7

Zhang, X., Lin, L., Zhang, T., \& Liu, H. (2016). Catalytic dehydration of lactic acid to acrylic acid over modified ZSM-5 catalysts. Chem. Eng. J., 284, 934-941. https://doi.org/10.1016/j.cej.2015.09.039

Zhao, H., Zuo, C., Yang, D., Li, C., \& Zhang, S. (2016). Effects of Support for Vanadium Phosphorus Oxide Catalysts on Vapor-Phase Aldol Condensation of Methyl Acetate with Formaldehyde. Ind. Eng. Chem. Res., 55, 12693-12702. https://doi.org/10.1021/acs.iecr.6b03079

Р. В. Небесный

Национальный университет "Львовская политехника", г. Львов, Украина

\title{
ПРОИЗВОДСТВО АКРИЛОВОЙ КИСЛОТЫ: СРАВНЕНИЕ ПРОМЫШЛЕННОГО И НОВЫХ ПЕРСПЕКТИВНЫХ МЕТОДОВ ЕЕ ПОЛУЧЕНИЯ
}

\begin{abstract}
Выполнен сравнительный обзор основных перспективных методов получения акриловой кислоты. Показано, что значительное развитие, учитывая доступность сырьевой базы, имеет метод получения акриловой кислоты из глицерина (побочного продукта производства биодизеля), а также путем ферментации биомассы. Кроме того, показано, что совершенствование катализаторов альдольной конденсации уксусной кислоты с формальдегидом в акриловую кислоту делает данный метод ее синтеза одним из самых конкурентных. Установлено, что модификация пористой структуры $\mathrm{B}-\mathrm{P}-\mathrm{W}-\mathrm{V}-\mathrm{O}_{\mathrm{x}} / \mathrm{SiO} \mathrm{O}_{2}$ катализаторов процесса альдольной конденсации является действенным способом влияния на их каталитические свойства. Оптимальным размером пор $\mathrm{B}-\mathrm{P}-\mathrm{W}-\mathrm{V}-\mathrm{O}_{\mathrm{x}} / \mathrm{SiO}_{2}$ катализаторов является 11-16 нм. В оптимальных условиях (температура $380{ }^{\circ} \mathrm{C}$, время контакта 8 c) выход акриловой кислоты в процессе альдольной конденсации уксусной кислоты с формальдегидом составляет 68 \% при селективности ее образования $91 \%$. Разработанный катализатор также является эффективным в процессе окислительной конденсации метанола с уксусной кислотой. Особенностью данного метода является то, что в процессе образуются одновременно два ценные продукты - акриловая кислота и метилакрилат. Суммарный выход акрилатов составляет 54,7 \% при селективности их образования $80,1 \%$ (температура $400{ }^{\circ} \mathrm{C}$, время контакта 8 с). Приведены перспективы использования новейших Se-содержащих каталитических систем на микрогелевой основе для низкотемпературного синтеза акриловой кислоты и метилакрилата с акролеина.
\end{abstract}

Ключевые слова: акрилатные мономеры; альдольная конденсация; акролеин; окисление; гетерогенные катализаторы.

R. V. Nebesnyi

Lviv Polytechnic National University, Lviv, Ukraine

\section{ACRYLIC ACID PRODUCTION: COMPARISON OF INDUSTRIAL AND NEW PROMISING METHODS OF ITS SYNTHESIS}

In this work comparative overview of the main promising methods of acrylic acid production is performed. Due to availability of the raw materials, base the development of acrylic acid production methods from glycerine (by-product of biodiesel production), as well as by fermentation of biomass, has become significant. In addition, it is shown that the improvement of the catalysts for aldol condensation of acetic acid with formaldehyde into acrylic acid makes this method of acrylic acid synthesis one of the most competitive. It is established that modification of $\mathrm{B}-\mathrm{P}-\mathrm{W}-\mathrm{V}-\mathrm{O}_{\mathrm{x}} / \mathrm{SiO}_{2}$ catalysts porous structure for the process of aldol condensation is an effective way of influencing their catalytic properties. Increasing of catalysts performance is mostly associated with changing of pore size distribution of the catalysts surface. In addition to increase of mechanical strength of silica gel granules subjected to hydrothermal treatment, reduction of coke formation takes place. The optimal pore size of $\mathrm{B}-\mathrm{P}-\mathrm{W}-\mathrm{V}-\mathrm{O}_{\mathrm{x}} / \mathrm{SiO}_{2}$ catalysts is $11-16 \mathrm{~nm}$. Such porous structure is achieved after hydrothermal treatment of silica support at the temperature range $125-175^{\circ} \mathrm{C}$ for $3 \mathrm{~h}$. Under optimal reaction conditions (temperature $380{ }^{\circ} \mathrm{C}$, contact time $8 \mathrm{~s}$ ) the yield of acrylic acid in the process of aldol condensation of acetic acid with formaldehyde is $68 \%$ with $91 \%$ selectivity of its formation. Created catalysts are also efficient in oxidative condensation process (oxidative condensation of methanol with acetic acid to acrylic acid and methylacrylate). The feature of this process is simultaneous obtaining of two valuable monomers - acrylic acid and methylacrylate. The total yield of acrylates is $54.7 \%$ with $80.1 \%$ selectivity of their formation (temperature $400{ }^{\circ} \mathrm{C}$, contact time $8 \mathrm{~s}$ ). The paper also shows the prospects for using the newest Se-containing catalytic systems on a microgel basis for low-temperature synthesis of acrylic acid and methyl acrylate from acrolein. Use of these catalysts allows us to convert acrolein to acrylic acid or methylacrylate (in methanol medium) at high one pass yield as well as high selectivity (up to $97 \%$ ).

Keywords: acrylate monomers; aldol condensation; acrolein; oxidation; heterogeneous catalysts. 